University of Rhode Island

DigitalCommons@URI

Open Access Master's Theses

1967

\title{
Investigation of a Phase-Coded Pulse Compression Technique for Improved Unambiguous Sonar Transmission
}

Samuel Dow Anthony

University of Rhode Island

Follow this and additional works at: https://digitalcommons.uri.edu/theses

\section{Recommended Citation}

Anthony, Samuel Dow, "Investigation of a Phase-Coded Pulse Compression Technique for Improved Unambiguous Sonar Transmission" (1967). Open Access Master's Theses. Paper 1358.

https://digitalcommons.uri.edu/theses/1358

This Thesis is brought to you for free and open access by DigitalCommons@URI. It has been accepted for inclusion in Open Access Master's Theses by an authorized administrator of DigitalCommons@URI. For more information, please contact digitalcommons-group@uri.edu. 
TKS 102.5

A584

INVESTIGATION OF A PHASE-CODED PULSE COMPRESSION TECHNIQUE FOR IMPROVED UNAMBIGUOUS SONAR TRANSMISSION

\author{
BY \\ SANUUEL DOW ANTHONY
}

A THESIS

SUBMITTED IN PARTIAL FULFILIMENT

OF THE

REQUIRENENTS FOR THE DEGREE OF

MASTER OF SCIENCE

IN

ELECTRICAL ENGINEERING

UNIVERSITY OF RHODE ISLAND

1967 
MASTER OF SCIENCE THESIS

$\mathrm{OF}$

SAMUEL DOW ANTHONY

APPROVED:

THESIS COMIMITTEE

CHAIRMAN

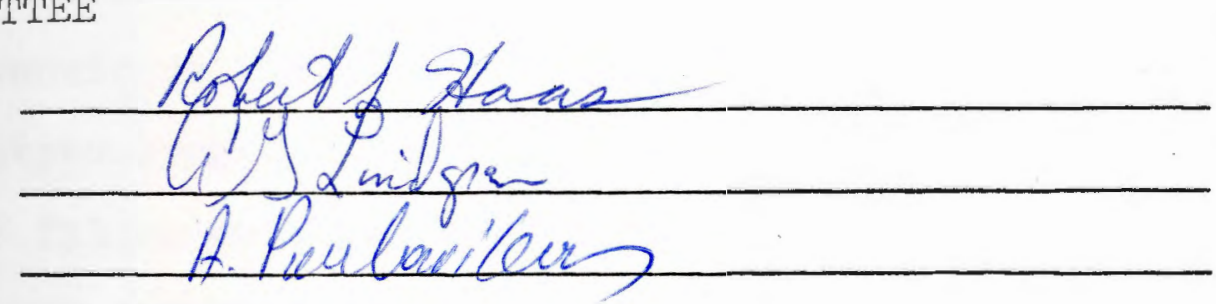

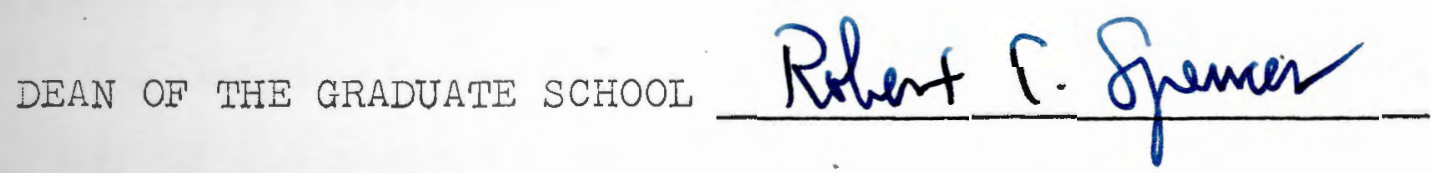

UNIVERSITY OF RHODE ISLAND

1967 
Most transmitters are peak-power limited due to the maximum allowable peak power to the transducer. A higher average power can be achieved with these transducers by keeping the same peak power but increasing the pulse width. This allows the range of the sonar system to be increased, however, the range accuracy is degraded due to the larger pulse width.

A common method of improving the range information is Pulse Compression. In effect, a wide pulse is transmitted with an FM component and, when received, is passed through a frequency-sensitive filter such that the higher frequencies will be delayed longer than the lower frequencies. The output of this filter exhibits a narrow pulse and thereby gives improved range information.

The range information of this narrow pulse is improved but not to the accuracy of a conventional pulse system due to the filter sidelobe effect which adds range ambiguities. These time sidelobes can be reduced by the use of sidelobe weighting filters, but a loss in signal-to-noise ratio results.

If the phase-coded pulse system proposed herein were used, the received decoded pulse would theoretically have unambiguous range information and the signal-to-noise ratio would depend only upon the total number of bits in the coded pulse. 
A brief description of FM pulse compression is given for background reference, followed by the proposed Phasecoded (PC) method. The logical development and mathematical substantiation of the $P C$ method is presented with various analytical treatments.

The doppler dispersion effect, which is present whenever relative motion between target and source exists, is analyzed for various pulse code widths. A relationship between relative target speed and pulse amplitude is derived such that operational parameters may be determined. The sidelobe effect, which is present in both the FM. and PC methods, is discussed and a method of elimination is developed for the PC system. Sidelobe elimination does have an effect on the signal-to-noise ratio, and a comparison is made between the two methods on this basis; along with the standara basis of comparison. 
Topic

Page

Abstract

Introduction

I Brief Description of FN Pulse Compression

II Proposed Method

5

9

II Doppler Dispersion Effect

18

IV Sidelobe Elimination 26

V Signal-to-Noise Comparisons 30

VI Conclusions

32

Bibliography

34

Appendix A - Computations

37 
Page

I-1 Various FII Pulse Compression Waveforms

Descriptive Characteristics of an FM Pulse

8

$1-2$

Transmitted and Recombined PCPC Waveform

10

$2-1$

Delayed and Recombined Coded Pulse for a 7-Bit Code

11

2-3 Arrangement for Determining the Bit Phase Relationships

11

2-4 Amplitude Representation of Reconstructed Code Group

13

2-5 Amplitude Representation of Reconstructed Code Group

2-6 Normalized Transmitted and Recombined Waveforms

2-7 Proposed System Block Diagram 16

3-1 Phasor Diagram: Relative Bit Positions re. to Zero Doppler Shift

3-2 Amplitude vs. Phase Shift for 7-Bit Code

22

3-3 Amplitude vs. Phase Shift for 11-Bit Code

23

3-4 Amplitude vs. Phase Shift for 13-Bit code

24

4-1 Phase-Coded System Block Diagram with Sidelobe Elimination

28

4-2 Logic Representation of the Limiting Subtractor 


\section{DEDICATION}

This dissertation is dedicated to Patricia, whose -ouragement and understanding task that much more worthwile. 


\section{ACKNOWLEDGMENT}

The aid and criticism, which necessitate time, effort, and patience, of R. S. Haas (Major Professor) and Professors A. G. Iindgren and A. Poularikas are greatly appreciated and acknowledged. Also, to Dean E. Christie, who, on his own time, spent long hours setting up the computer program contained in this thesis, I give my very appreciative thanks. 


\section{INTRODUCTION}

Since the advent of sonar, there has been an everpresent requirement for increased transmitted power. The obvious reasons for this being the desire for stronger echo returns and/or greater effective range. It can be seen from this that a limit of maximum power available will be reached. From the typical transducer data in the appendix, It can be seen that the maximum power limit reached is the maximum allowable peak power to the transducer. Closer inspection shows that a higher transmitted power can be achieved by increasing the transmitted pulse width. This is due to the fact that increasing the pulse width at the maximum input power level does not exceed the maximum average input power. It is assumed that the pulse duration is much less than the pulse period, which is true for almost all active sonar applications.

The increased pulse width does allow for increased sonar range but degrades the range resolution of the target. This can be seen by referring to R. J. Schlesinger's zotes of Electronic Warfare, ${ }^{1}$ in which $1 t$ is shown that an optimum bandwidth exists and is related to the reciprocal of the pulse width such that optimum signal to noise is achieved. If, for instance, the pulse width were 1ncreased by a factor. of four, the optimum receiver bandwidth would be one quarter of its previous width. The amplitude of the received pulse would still be the same, 
quarter of its previous power level (assuming Gaussian distribution across the band of interest), resulting in a net $6 \mathrm{db}$ signal-to-nolse increase. Schlesinger points out that the pulse waveform out of this bandpass filter is no longer rectangular in shape but more like a $(\sin x) / x$ shape. The range resolution of the echo is four times longer than that of the original due to the increased pulse width. This loss in range resolution can be eliminated by the use of a pulse compression technique. The most common method in radar applications is FV pulse compression which is discussed briefly in Chapter I. For sonar applications, however, the FN method is doomed to limited use due to the multipath cancellation effect described in J. W. Horton's Fundamentals of Sonar. 2 Horton concluded that due to the wide phase variation of the FM pulse and the multiple paths traveled by the acoustic energy, there is very severe distortion of the waveform. For this reason, an FM type of pulse compression is not widely used in sonar applications. In October 1962, as a novel approach to radar pulse compression, C. F. Phillips ${ }^{3}$ presented a four-bit variable width, single erequency pulse compression technique without mathematical development. This is not an uncommon practice in the field of science. In many instances, mathematical substantiation occurs after a phenomenon has been observed. It is concelvable that any code group can be developed by trlal and error. This particular code (four-bit variable 
width) actually consisted of seven, fixed-width bits, which I: the text will be called the 7-bit code, that by trial and error would have $2^{7}$ possible combinations. Of these 128 comblnations, half are mirror images of the other half (this mpror 1mage relationship is explained in Chapter II). Of these 64 possible combinations, half are code groups 180 jegrees out of phase with the other half. Therefore, a trial and error method requires a maximum of 32 attempts before the proper code group is found. Thus, the number of trials for an $\mathrm{N}$-bit code would be $2^{\mathrm{N}-2}$. Obviously, there is a need for a method with which to determine the various code 3roups for different code widths. This is done in chapter I.

The encoding and decoding of the 4-bit variable width code was successfully done by Phillips whose system block diagram consisted of the encoder and decoder portions of the proposed system shown in Chapter II. A search of the Ilterature has disclosed no further publications concerning other possible code groups of the type contained in the text. This could be due to a variety of reasons. However, it should be noted that in radar, FM pulse compression can provide a higher compression ratio than would a 7-bit code (refer to chapter I), and thereby necessitate a larger number of bits in the code, which, as previously mentioned, would be that much more difficult to determine. It should be noted also that FV pulse compression in radar is not adversely affected by the media while it would be by the sea 
sonar application. This may be the reason for the avid pursilt of the phase-coded pulse compression system for sonar use rather than for radar use.

The phase-coded method of pulse compression depends on a single, flxed frequency with abrupt phase changes of \pm 180 degrees, whereas the FV method depends upon a variable phase shift across the transmitted pulse (see Chapter I), leading to Horton's explanation of multipath cancellation. If nothing else, this observation shows that the multipath cancellation would appear to have a less severe effect on the phase-coded pulse waveform.

The mechanics and basic behavior of FM pulse compression are presented in Chapter I for background. Then, the phasecoded method is developed by the author in Chapter II which includes the derivation of the general equations for determining the various code groups.

Doppler dispersion, due to relative motion between target and source, has a measurable effect on the phasecoded system if the operational parameters are not judiciously chosen. Chapter III presents this effect through the author's development of an equation relating received pulse amplitude and doppler phase shift. A computer plot and its graphical presentation of this equation is made for three different codes.

A treatment is given to sidelobe effects and signal-tonolse ratios in Chapters IV and $V$, respectively. This is done on a comparison basis between FM and PC pulse compression. 
BRIEF DESCRIPTION OF FM PULSE COMPRESSION

FM pulse compression is an already proven method and is quite suitable for radar applications. However, there are some drawbacks as far as sonar use is concerned, other than the characteristics of the channel media. The three basic disadvantages are: multipath cancellation, doppler dispersion, and the acoustic attenuation properties of the water. Reverberation is an effect caused by the transmitted pulse returning from unwanted discontinuities in the media (i.e., s1gnal bouncing back and forth between discontinuity and source). It cannot be directly eliminated by FM pulse compression, phase-coded pulse compression, or the conventional method of transmission, and therefore will not be discussed topicly.

Complexity of design is not considered a drawback to the FM system. For the sake of simplicity, only linear FM pulse compression will be considered in the comparisons.

C. E. Cook ${ }^{4}$ very aptly presents the fundamentals of FM pulse compression. Flgures $1-1$ and $1-2$ are excerpts from Cook's publication. The following definitive characteristics will be used for clarity and comparative purposes:

1. After pulse recombination, the ampiitude and spectral responses are both of the $(\sin x) / x$ form.

2. The pulse compression ratio is

$$
\left(T / t^{i}\right)=B W T
$$


where $T$ is the transmitted pulse length

$t^{\prime}$ is the recombined pulse width

BW is the bandwidth scanned in $T$

3. The transmitted pulse amplitude is unity.

4. The reconstmcted amplitude is

$$
A=(B W T)^{1 / 2}
$$




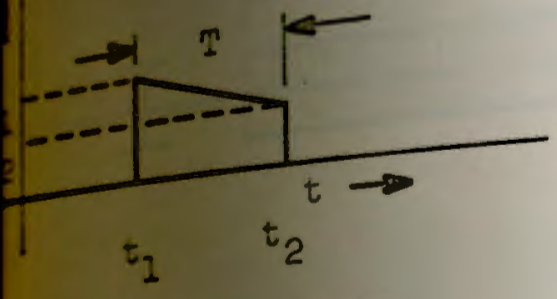

Ireq. vs. Time

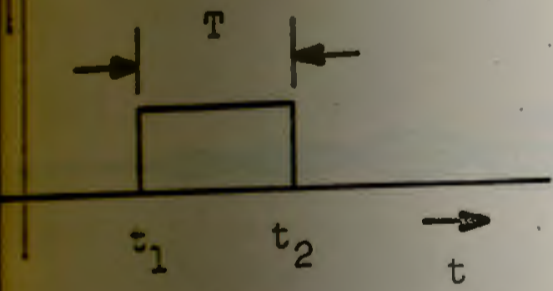

Scansulted Pulse Ampl. vs. TIme

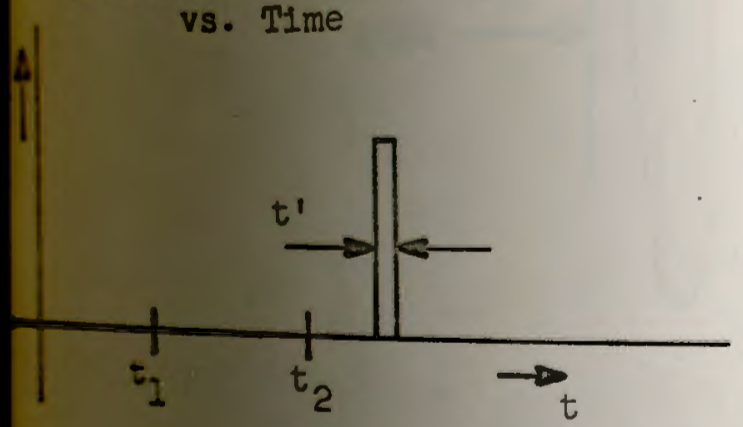

Ideal Reconstructed Pulse

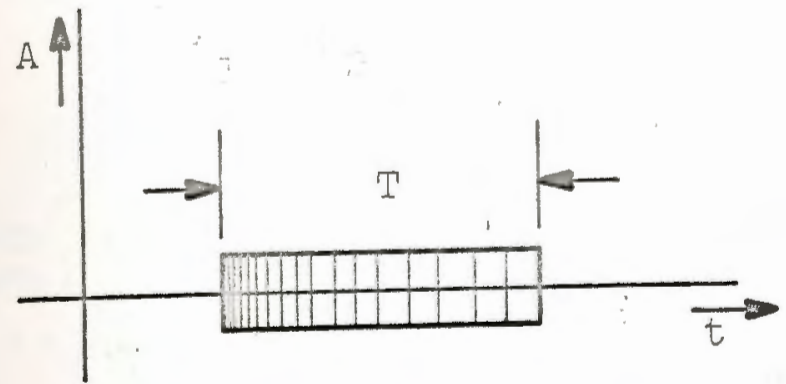

Transmitted Carrier

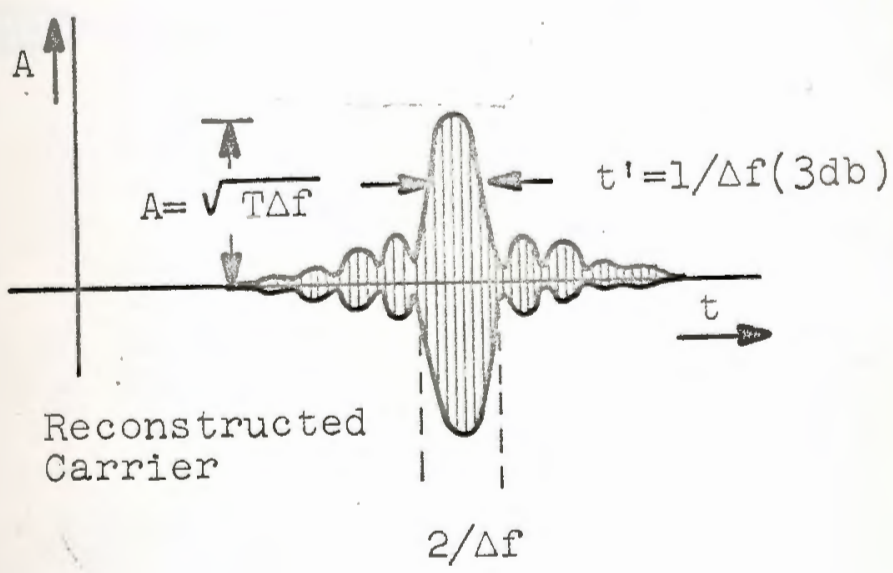

Doure I-I Various FN Pulse Compression Waveforms 
r

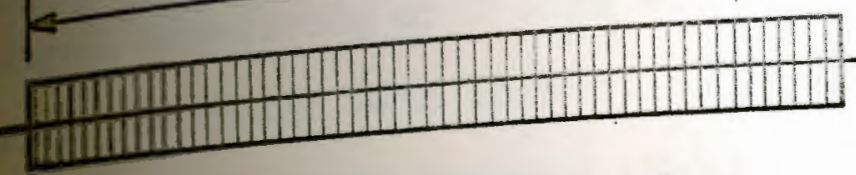

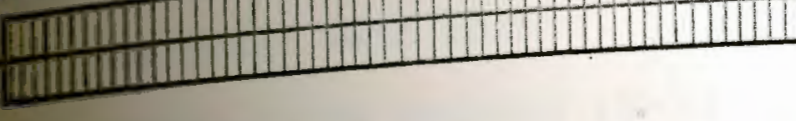
I

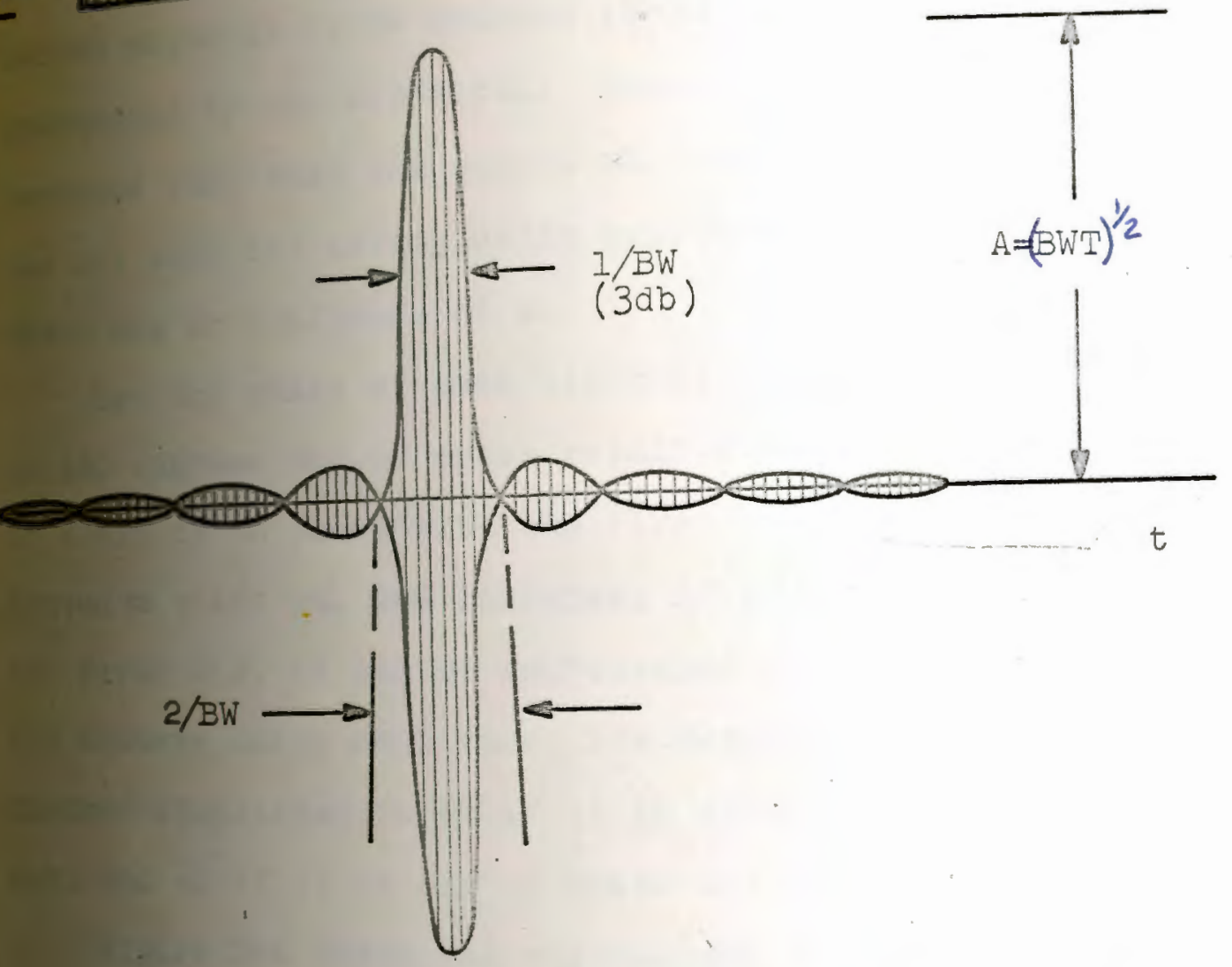

Compression Ratio=T/t=BWT.

Pigure 1-2 Descriptive Characteristics of an FM Pulse 
The proposed method will involve transmitting a pulsed cW signal consisting of $\mathrm{N}$ bits either in phase or 180 degrees out of phase with respect to the first bit. The recelved pulse is to be delayed $(\mathrm{N}-\mathrm{I})$ times, with each delay increasing by one bit width. These delayed pulses are then combined such that the output will be $N$ narrow pulses, each one bit wide and having unity amplitude, except for one which has an amplitude of $\mathrm{N}$.

Let the phase of each bit position be either in phase or 180 degrees out of phase relative to the first bit. Now, If a bit is in phase with the first bit, it can be represented as a(sin wt), and likewise, if it is out of phase with the first bit, it can be represented as $-a(s i n w t)$. If each b1t assumes unity amplitude, its representation can be further simplified to +1 if it is in phase with the first bit, and -1 if it is out of phase with the first bit.

Bigure 2-1 shows the phase-coded waveform along with Its assoclated logic (Figure 2-2). 


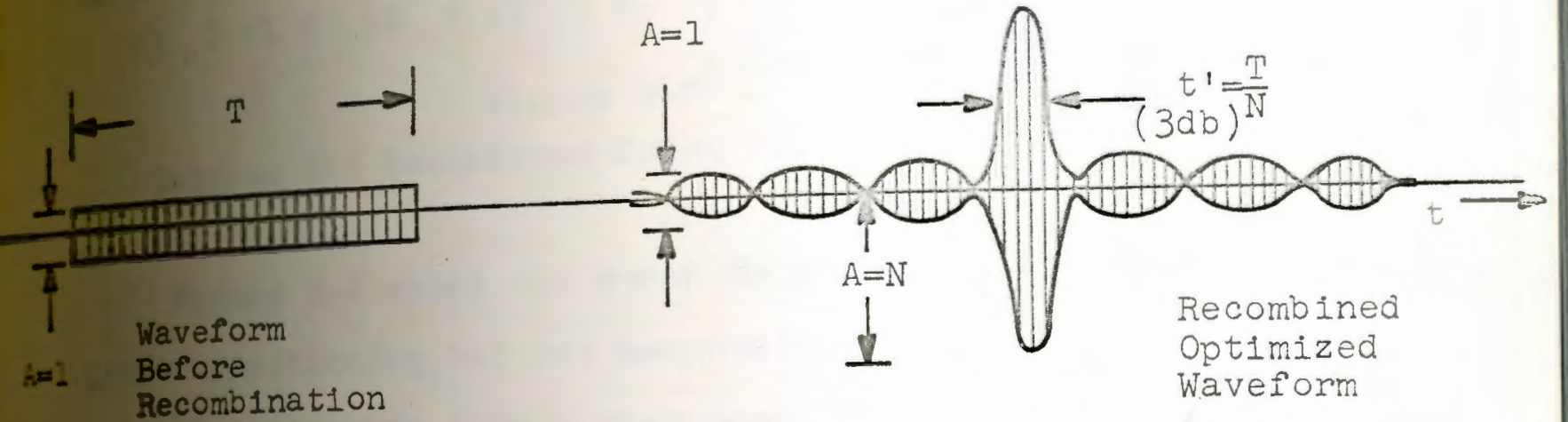

Pigure 2-1 Transmitted and Recombined PCPC Waveform 


$$
\begin{aligned}
& \pm\left(\begin{array}{lllllll}
a & b & c & d & e & f
\end{array}\right) \\
& \pm\left(\begin{array}{lllllll}
a & b & c & d & e & f & g
\end{array}\right)
\end{aligned}
$$

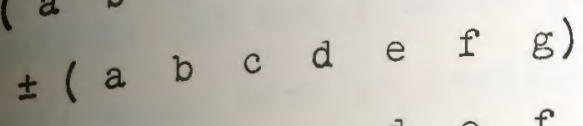

$$
\begin{aligned}
& \pm(a b b \quad d \quad e \quad f \quad g) \\
& \pm(a b c d e f r) \\
& \pm\left(\begin{array}{lllllll}
a & b & c & d & e & f & g
\end{array}\right)
\end{aligned}
$$

Code Groups and their Associated Delays

$\pm 10 \pm 10 \quad \pm 1 \quad 0 \pm 7 \quad 0 \pm 1 \quad 0 \pm 1 \quad 0 \pm 1$ Output Relationship

$$
\text { Figure 2-2 }
$$

Delayed and Recombined Coded Pulse for a 7-Bit Code

B1gure 2-2 shows the seven delayed code groups with the proper positioning but not necessaxily with the proper phase relationship (the proper phase of each group is necessary in order to achieve the output relationship shown in P1gure 2-2). If we multiply each row by its corresponding b1t and altemately change group phase, then the results are as ahown in Figure $2-3$.

ab ac ad ae af ag

$$
-b a-b b-b c-b d-b e-b f-b g
$$

ca $c b$ cc cal ce of $a g$

$$
-d a-d b-d c-d d-d e-d f-d g
$$

ea eb. ec ed ee ef eg

$$
-f a-f^{\prime} b-f c-f^{\prime} d-f e-f f-f g
$$

ga gb gc gd ge gf gg

$$
\begin{aligned}
& \begin{array}{llllllllllllll}
1 & 0 & 1 & 0 & 1 & 0 & \pm 7 & 0 & 1 & 0 & 1 & 0 & 1 & \text { output }
\end{array} \\
& \text { Figure 2-3 }
\end{aligned}
$$


It can be seen from Figure $2-3$ that $a d=1$ and $-d d=-1$ and, therefore, $a g-b f+c e-d d+e c-f b$ tga must equal - 7 for oumm output. It can also be seen that all of the even columans w1l equal zero by definition. The leading bit 'a' can be arbitrarily chosen as +1 or -1 ; for this analysis, we v11 chose ' $a$ ' to be +1 .

$$
a=1
$$

From the third column:

$$
2 a c-1=1 \quad \text { therefore, } c=1
$$

From the fifth column:

$$
2 a e-2 b d+1=1 \text { therefore, } e=b d
$$

From the seventh column:

$$
\begin{array}{ll}
a g=-1 & \text { therefore, } g=-1 \\
-b f=-1 & \text { therefore, } b f=1 \\
c e=-1 & \text { therefore, } e=-1
\end{array}
$$

Thus, yielding from equation $2-3$,

$$
b=-d
$$

and from equation 2-5,

$$
b=f
$$

Brom this analysis, the 7-bit code can now be determined. Our equations require only that the product of $b$ and 1 be equal to 1 , and the product of $b$ and $d$ be -1 . Therefore, we w111 set up two sequences; one where $b$ equals +1 and the other where $\mathrm{b}$ equals -1 .

$$
\begin{aligned}
& \text { Code where b equals }+1 \text { : } \\
& \qquad+1+1+1-1-1+1-1
\end{aligned}
$$


code where $b$ equals -1 :

$$
+1-1+1+1-1-1-1
$$

It can be seen that these codes are symetrically identical because of the fact that the output waveform is symetIncal about the main lobe. The respective outputs are as shown in sigures $2-4$ and $2-5$.

$+1+1+1 \quad-1 \quad-1+1 \quad-1$

$$
\begin{array}{rrrrrrrrrrrrrrrrr}
-1 & -1 & -1 & +1 & +1 & -1 & +1 & & & & & \\
& +1 & +1 & +1 & -1 & -1 & +1 & -1 & & & & \\
& +1 & +1 & +1 & -1 & -1 & +1 & -1 & & & \\
& & -1 & -1 & -1 & +1 & +1 & -1 & +1 & & & \\
& & -1 & -1 & -1 & +1 & +1 & -1 & +1 & \text { Code }(2-8) \\
& & & -1 & -1 & -1 & +1 & +1 & -1 & +1 &
\end{array}
$$

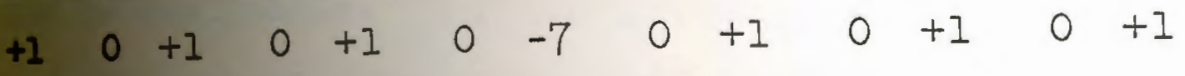

$$
\text { Figure 2-4 }
$$

Amplitude Representation of Reconstructed Code Group

$$
\begin{aligned}
& +1 \quad-1+1+1 \quad-1 \quad-1 \quad-1 \\
& \begin{array}{lllllll}
+1 & -1 & +1 & +1 & -1 & -1 & -1
\end{array} \\
& +1-1+1+1-1 \quad-1-1 \\
& \begin{array}{lllllll}
-1 & +1 & -1 & -1 & +1 & +1 & +1
\end{array} \\
& -1+1 \quad-1-1+1+1+1 \\
& \begin{array}{lllllll} 
& -1 & +1 & +1 & -1 & -1 & -1
\end{array} \\
& \begin{array}{lllllll}
-1 & +1 & -1 & -1 & +1 & +1 & +1
\end{array}
\end{aligned}
$$

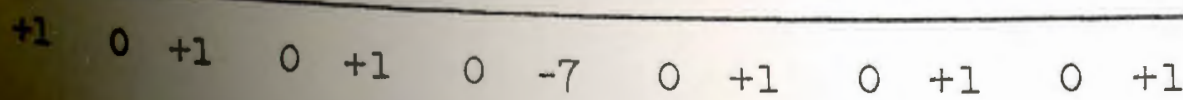

$$
\begin{aligned}
& \begin{array}{l}
\text { Figure } 2-5 \\
\text { Amplitude Representation of Reconstructed Code Group }
\end{array}
\end{aligned}
$$


If 'a' were chosen to be -1 rather than +1 , the code grentation would be as follows:

$-1-1-1+1+1-1+1$

$-1+1-1 \quad-1+1+1+i$

The corresponding output for equations 2-10 and 2-11

w11 be as follows:

$\begin{array}{lllllllllllll}-1 & 0 & -1 & 0 & -1 & 0 & +7 & 0 & -1 & 0 & -1 & 0 & -1\end{array}$

Bgure 2-6 shows the normalized transmitted and recombined wafeforms. Figure $2-7$ shows the proposed system block

\section{d1agram.}

As a point of interest, by definition, the total number of bits cannot be an even amount. If there were an even number of bits, the recombined waveform of Figure 2-1 would not be realizable.

In general, the phase code is as follows:

$\begin{array}{llllllllll}a_{1} a_{1} & a_{1} a_{2} & a_{1} a_{3} & a_{1} a_{4} & a_{1} a_{5} & \cdots & a_{1} a_{m} & \cdots & a_{1} a_{N}\end{array}$

$r_{2} a_{1}-a_{2} a_{2}-a_{2} a_{3}-a_{2} a_{4}-a_{2} a_{5} \quad \ldots-a_{2} a_{m} \ldots-a_{2} a_{N}$

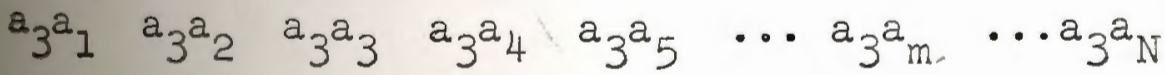

.

$-i^{2 m} a_{m} a_{1}-i^{2 m} a_{m} a_{2} \cdots-i^{2 m} a_{m} a_{m} \cdots-i^{2 m} a_{m} a_{N}$

$a_{N} a_{1} a_{N} a_{2} \cdots a_{N} a_{m} \cdots a_{N} a_{N}$ 


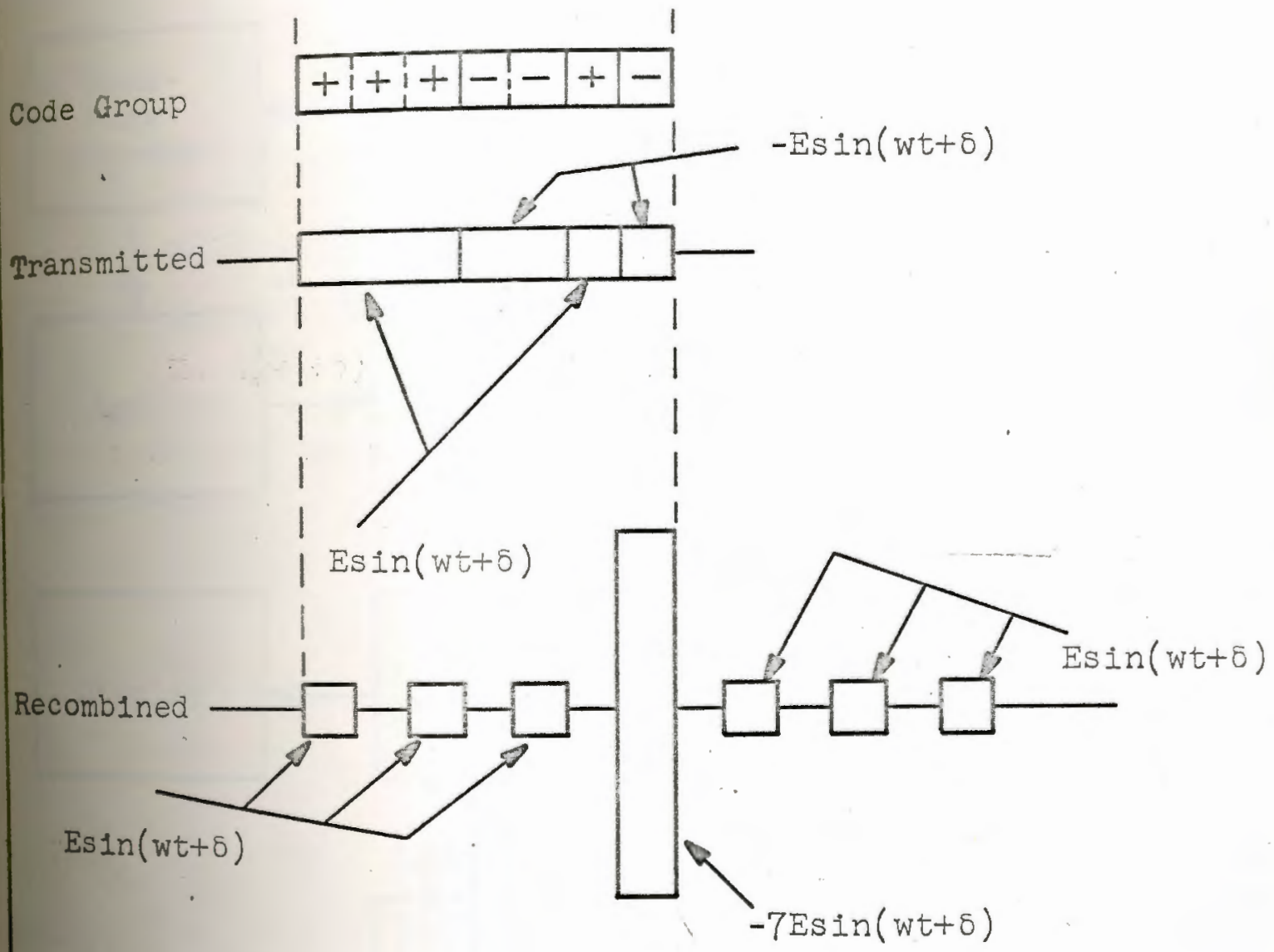

Figure 2-6 Normalized Transmitted and Recombined Waveforms 
Reference

Gate

1
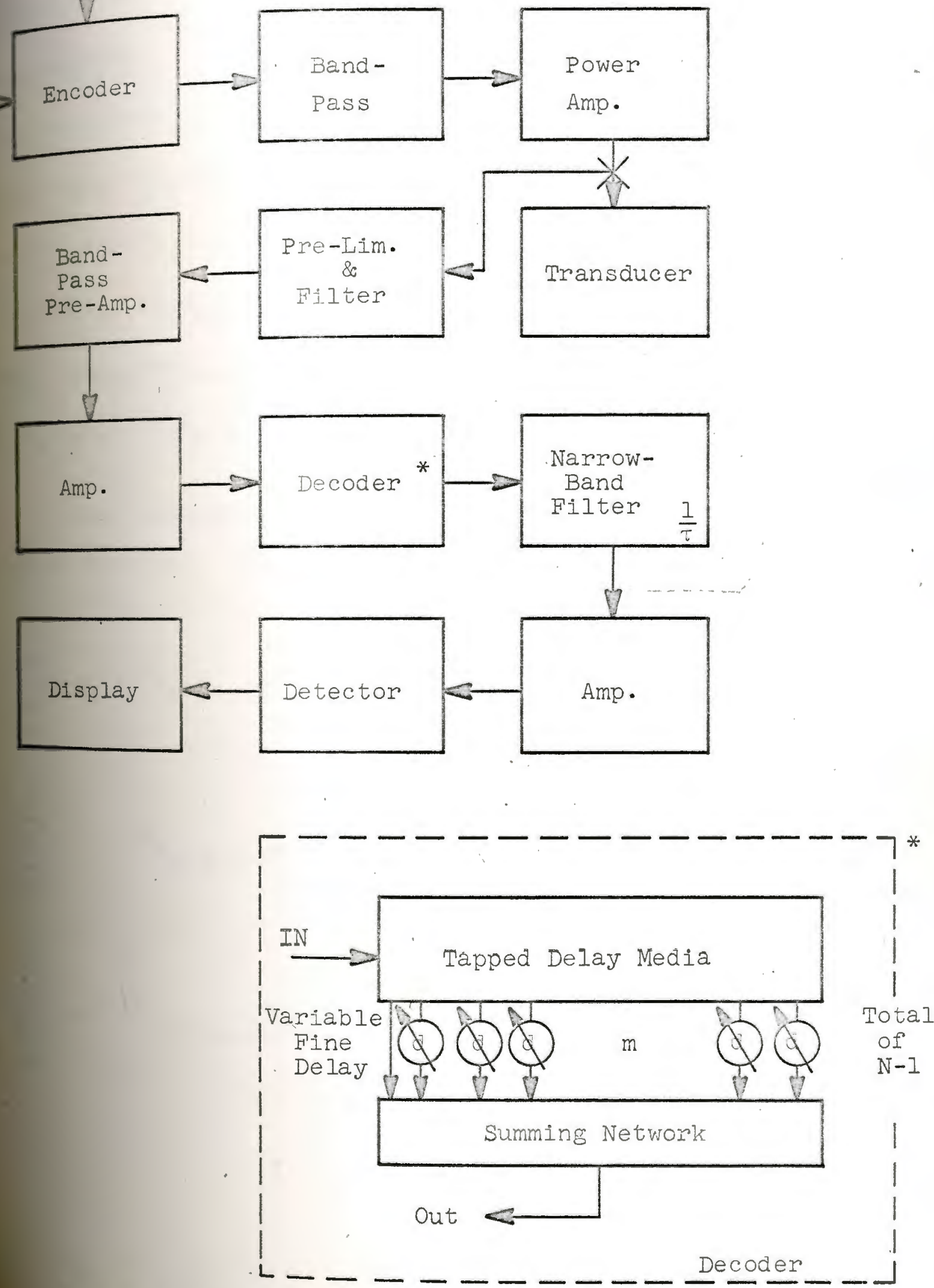

Figure 2-7 Proposed System 37ocle niacram 
and the equalities are

$$
\begin{aligned}
& a_{1} a_{1}=1 \\
& a_{1} a_{2}-a_{2} a_{1}=0 \\
& a_{1} a_{3}-a_{2} a_{2}+a_{3} a_{1}=1 . \\
& a_{1} a_{4}-a_{2} a_{3}+a_{3} a_{2}-a_{4} a_{1}=0 \\
& a_{1} a_{5}-a_{2} a_{4}+a_{3} a_{3}-a_{4} a_{2}+a_{5} a_{1}=1 \\
& a_{1} a_{m}-a_{2} a_{m-1}+a_{3} a_{m-2}-a_{4} a_{m-3}+\ldots-a_{m} a_{1}=0 \text { (for } m \text { as an even number) } \\
& a_{1} a_{m}-a_{2} a_{m-1}+a_{3} a_{m-2}-a_{4} a_{m-3}+\ldots+a_{m} a_{1}=1 \text { (for } m \text { as an odd number) } \\
& \left|a_{1} \varepsilon_{1}-a_{2} a_{N-1}+a_{3} a_{N-2}-a_{4} a_{N-3}+\ldots+a_{N} a_{1}\right|=N
\end{aligned}
$$

From these general relations, the following equations can be derived:

$$
\begin{aligned}
& \text { 2n-1 } \\
& \text { where } n=1,2,3, \ldots \frac{N-1}{2} \text {, and } N=\text { total bits } \\
& \sum-(i)^{2 m} a_{m} a_{2 n-m}=1 \\
& m=1 \\
& \sum_{n=1}^{N} \\
& -(i)^{2 m} a_{m}{ }^{2}-m+1 \mid=N \\
& -(1)^{2 m} a_{m} a n-m+1=0
\end{aligned}
$$


Assume a target moving at a velocity ( $v$ ) relative to the receiving array. Then, from geometric analysis, the resultant doppler shift $(\Delta f)$ will be

$$
\Delta f=\frac{V}{C} f_{C}
$$

where $f_{c}$ is the transmitted frequency and $c$ is the speed of sound Fropagation in water.

The effective phase change $(\Delta \phi)$ in degrees will be

$$
\Delta \phi=360(\Delta f) t
$$

where $t$ is the bit width.

It should be noted at this time that $\Delta \dot{\phi}$ is the phase Affrerence between consecutive bits which is progressive as the bit position increases.

In 1 gure 3-1, the resultant effective amplitude is show for an $N$ bit code where the effective doppler phase shift is $\phi$. It can be seen from Figure 3-1 that A (the offective combined amplitude) will be equal to the root of the sum of the squares of the sums of the sides, 1.e.,

$$
\begin{aligned}
A^{2}=(\sin \phi+\sin 2 \phi+\ldots+\sin N \phi)^{2} & +(\cos \phi+\cos 2 \phi \\
& +\ldots+\cos N \phi)^{2}
\end{aligned}
$$


which in sigma notation is,

$$
A^{2}=\left\{\sum_{m=1}^{N} \sin m\right\}^{2}+\left\{\sum_{m=1}^{N} \cos m \phi\right\}^{2}
$$

Then, performing the square and recognizing similarities,

$$
A^{2}=\sum_{m=1}^{N} \sum_{n=1}^{N}[(\sin m \phi)(\sin n \phi)+(\cos m \phi)(\cos n \phi)]
$$

AppIying a trigonometric product identity,

$A^{2}=\sum_{m=1}^{N} \sum_{n=1}^{N} \cos (m-n) \phi$

Now, expanding into the individual terms,

$$
\begin{aligned}
A^{2}=\cos (N-1) \phi+\cos (N-2) \phi+\ldots+\cos (\phi)+1 \\
+\cos (N-2) \phi+\cos (N-3) \phi+\ldots+1+\cos (-\phi) \\
\vdots \\
+1+\cos (-\phi)+\cos (-2 \phi)+\ldots+\cos (2-N) \phi+\cos (1-N) \phi(3-6)
\end{aligned}
$$

which unites into

$$
\begin{aligned}
A^{2} & =N+2 \cos (N-1) \phi+4 \cos (N-2) \phi+\ldots+(2 m) \cos (N-m) \phi+\ldots \\
& +2(N-2) \cos (2 \phi)+2(N-1) \cos \phi
\end{aligned}
$$


Flnally, in sigma notation,

$$
A^{2}=N+\sum_{m=1}^{N-1}(2 m) \cos (N-m) \phi=N+2 \sum_{m=1}^{N-1}(N-m) \cos (m \phi)(3-8)
$$

2igures 3-2, 3-3, and 3-4 show the amplitude dependence upon phase for the 7-, 11-, and 13-bit codes, respectively. Due to the fact that equation $3-8$ is an even function, it is symetrical about the $Y$ axis in rectangular coordinates or the $0^{\circ}-180^{\circ}$ axis in polar coordinates.

\section{Eartical Example of the Doppler Dispersion Effect}

Given: $f=10,000 \mathrm{~Hz}$

$$
\begin{aligned}
& t=1 \mathrm{millisecond} \\
& c=5000 \mathrm{feet} / \mathrm{second}
\end{aligned}
$$

Find the velocity at which the received signal strength has decreased $3 \mathrm{~d}$ b from doppler effects alone.

From equations $3-1$ and $3-2$,

$$
V=(\Delta \phi)(c) /(360)(f)(t)
$$

Brom figure $3-2$, the $3 a b$ point is at $23^{\circ}$. Therefore, for the 7-bit code,

$$
\begin{aligned}
& v=(23)(5000) /\left(360(104)\left(10^{-3}\right)\right. \\
& v=31.94 \mathrm{ft} / \mathrm{sec} \cong 18.9 \mathrm{knots}
\end{aligned}
$$

From Figure $3-3$, the $3 \mathrm{dib}$ point is at $14.5^{\circ}$. Therefore, for the 1l-bit code,

$$
v=20.15 \mathrm{ft} / \mathrm{sec} \cong 11.9 \mathrm{knots}
$$




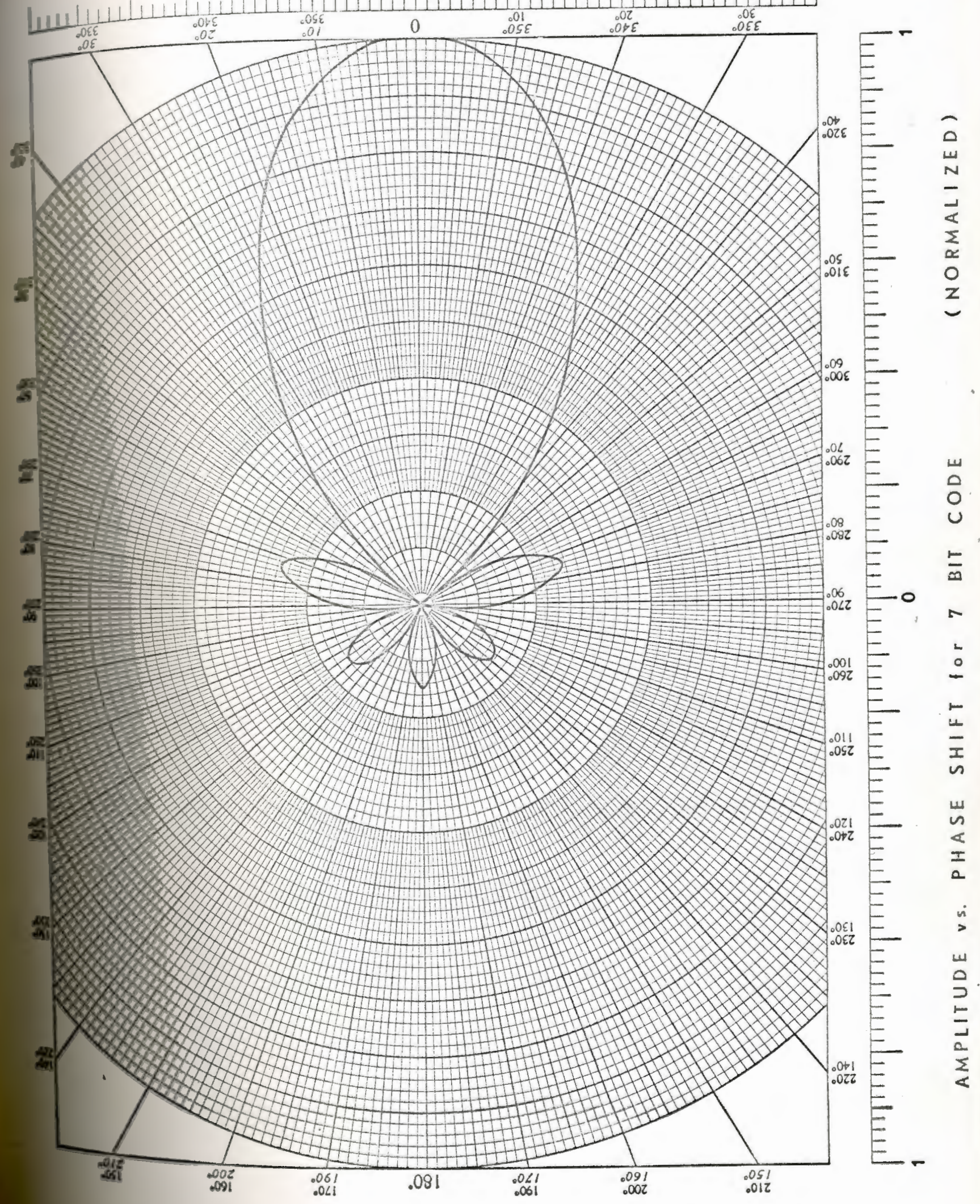




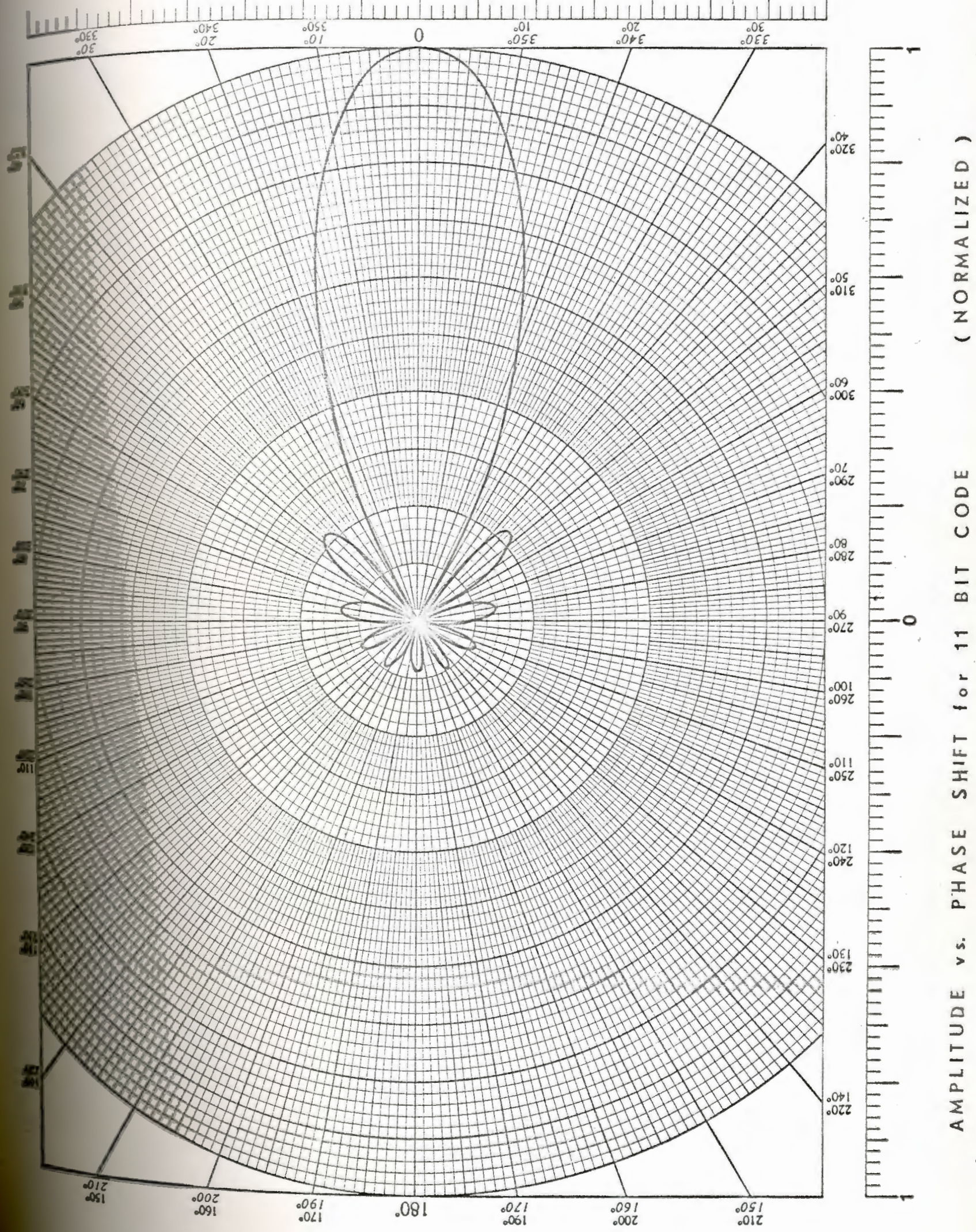




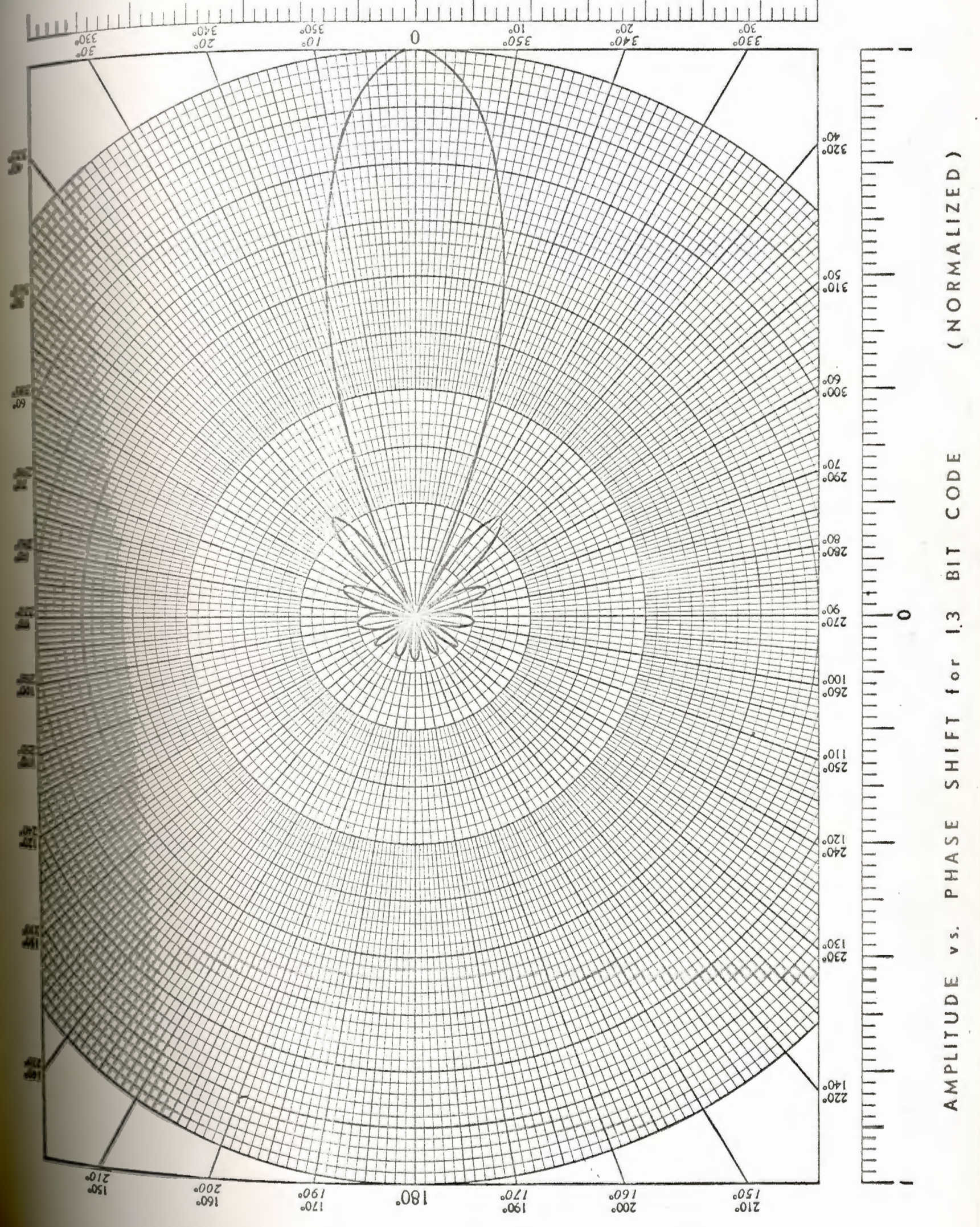


From Figure $3-4$, the $3 a b$ point is at $12.5^{\circ}$. Therefore, for the 13-bit code,

$$
v=17.40 \mathrm{ft} / \mathrm{sec} \cong 10.3 \mathrm{knots}
$$

As would be expected, the doppler effect does increase with increasing bits, given a fixed bit width.

It can be seen from this example that the reconstructed pulse will be seriously degraded" at speeds above ten knots. A more juaicious selection of operational parameters would produce an output less sensitive to doppler effects. For example, if the transmitting frequency were chosen to be $1000 \mathrm{~Hz}$ instead of $10 \mathrm{KHz}$, the three $3 \mathrm{db}$ velocities would be 189 knots, 119 knots, and 103 knots, respectively.

From equation 3-9 and Figures 3-1, 3-2, and 3-3, and the choice of maximum expected target speed, a fixed frequency-pulse duration proauct can be determined for satisfactory system performance. 


\section{SIDELOBE ELIMINATION}

The IM sidelobes can be eliminated by the use of special weighting filters as outlined by J. E. Chin and C. E. Cook. 4 These weighting filters are quite sophisticated in design and nature. Due to this sophistication, the weighting filter in most cases will reflect a large portion of the receiver cost. Unlike the FM sidelobes, the Phase-coded sidelobes have special characteristics: equal amplitude, same phase, and finite number of lobes. These characteristics allow for. sidelobe elimination by the use of a pre-limiter and limiting subtractor.

A block diagram of the Phase-Coded system, including the siclobe eliminator, is shown in Figure 4-1. Figure 4-2 shows the logic of the limiting subtractor.

The sidelobes of a strong echo will cause the main lobe or a weaker echo to have ambiguous range information. It is the purpose of the sidelobe eliminator to provide unambiguous range information for both strong and weak echos.

Another point of interest is that incorporation of a Phase-Coded system or FN system automatically provides an ECCV ${ }^{2}$ (Electronic Counter-Countermeasures) capability. The Phase-Coded system with its associated sidelobe eliminator provides the additional capability of automatic system noise level (i.e., the average receiver output noise level remains constant). This would make the system compatable with any 
future sonar signal processing equipment requiring constant misinformation rates. 
Reference

cate

wnoocen
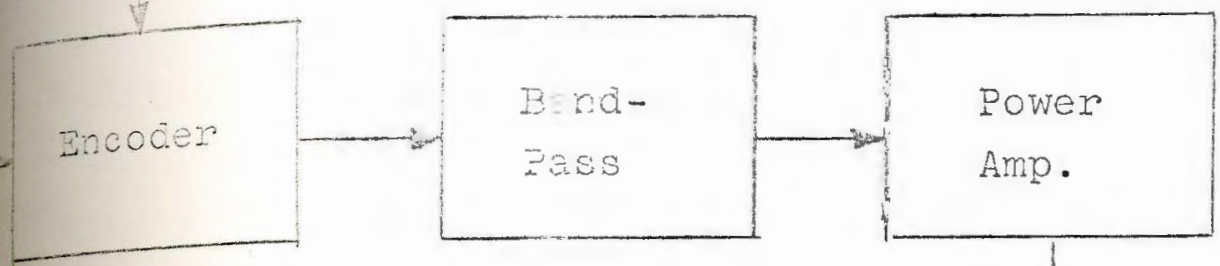

Band-

Pass

Pre-Amo.

\section{Pre-Ifin.} 3:

Fitier
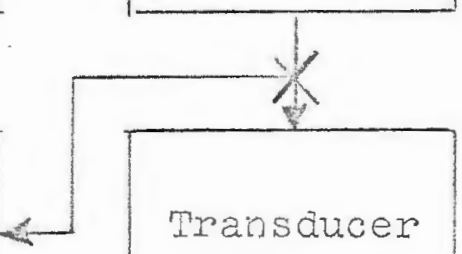

Transaucer

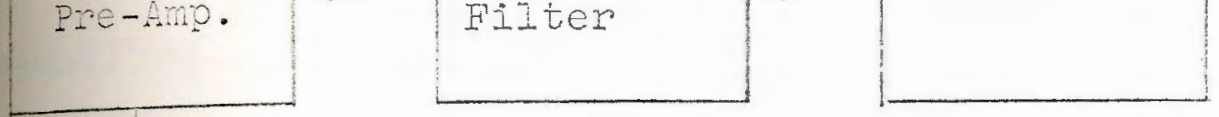

Decoder
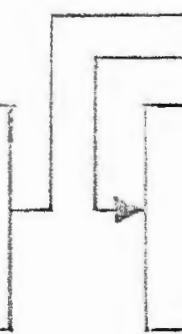

Narrow-

Band

Filter
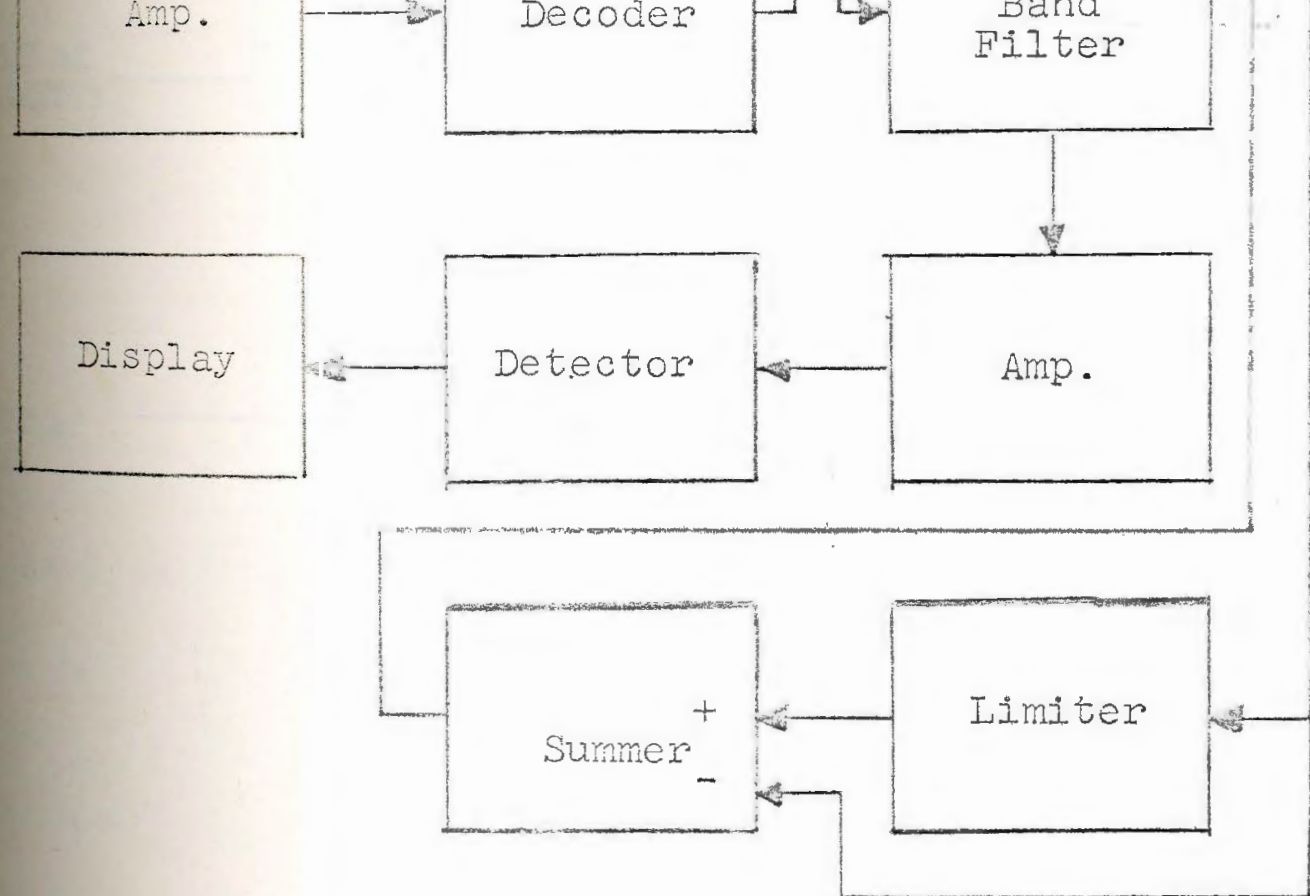

Hine $4-1$

Phase-Coded S. stem BIock Diagram

Wit. Sive one ifimination 


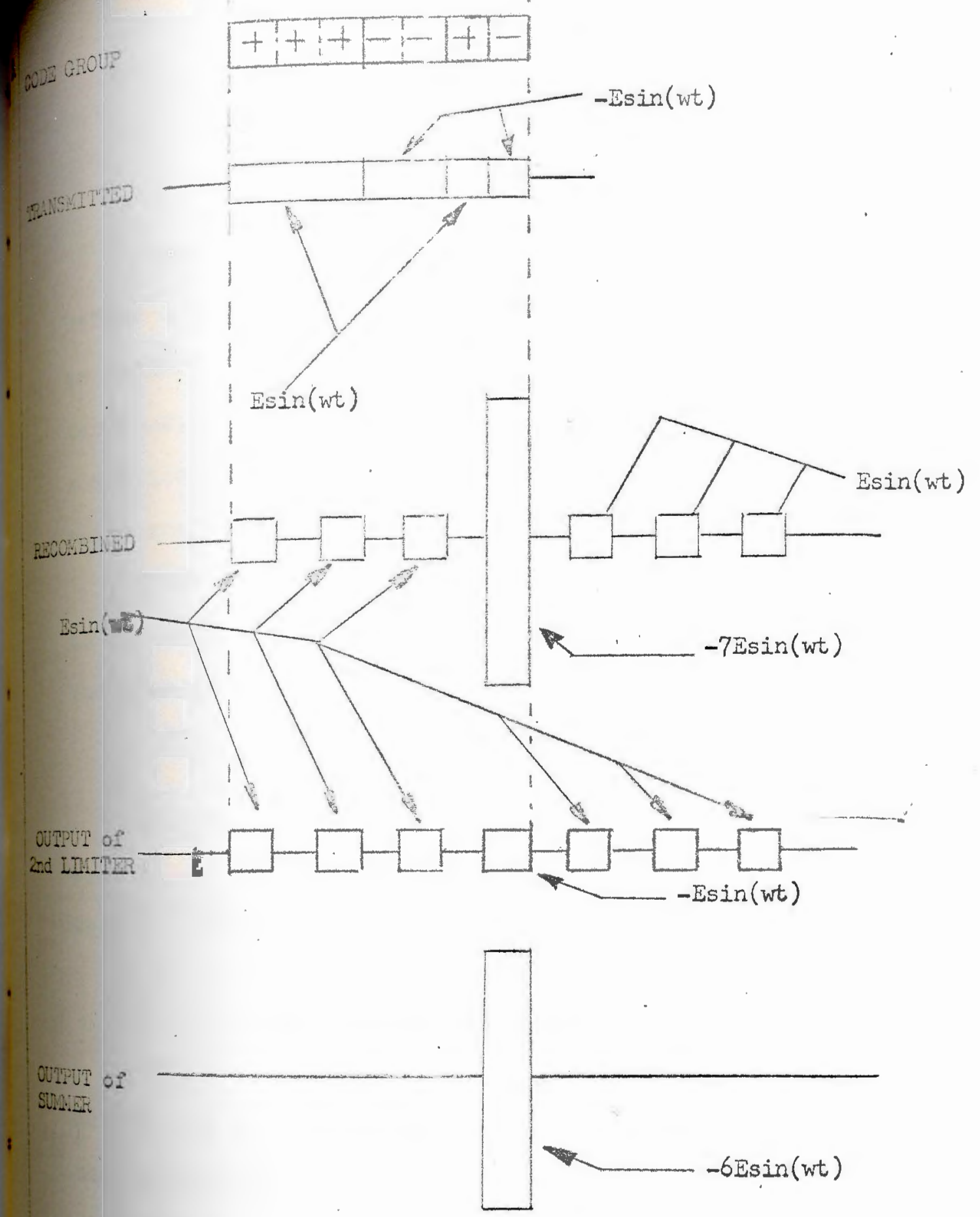

Fifuro 4-2 Logic Representation of the Iimiting Subtractor 
SIGNAI-TO-NOISE COMPARISONS

comparison will be made on the basis of pre-limiting before decoding or reconstruction. This is done such that an optimum clipping level will be assumed rather than determined. To determine the optimum clipping level would be a duplication of efforts already performed ${ }^{5}$ in the field of noise analysis.

From C. E. Cook ${ }^{4}$, the FM signal-to-noise ratio is equal to the square root of the product of the FN bandwidth and the transmitted pulse width,

$$
S / N=(B W T)^{1 / 2}
$$

The reconstructed amplitude of the Phase-Coded-pulse will be equal to the number of bits $(N)$. (See equation 3-8 when $\left.\phi=0^{\circ}.\right)$ From Figures $1-2$ and $2-1$, it is seen that

$$
N=B W T
$$

At first glance one would suspect that the pulse code method has a $S / N$ ratio $\sqrt{N}$ times greater. However, aue to the method of recombination, the effective roise level will increase by a factor of $\sqrt{N}$. It is stated by $F$. M. Reza 6 that for any randomly varying noise signal, the summation of such will yiela an expected output value equal to the square root of the sum of their means squared, i.e.,

$$
E(\text { Noise })=\left(\sigma_{1}^{2}+\sigma_{2}^{2}+\sigma_{3}^{2}+\ldots+\sigma_{n}^{2}\right)^{1 / 2}
$$


Note that we are taking a randomly varying signal whose comelation is zero everywhere except at $(t=0)$, and summing it at $\mathbb{N}$ different time intervals with no increase or decrease in expected amplitude. Therefore,

$$
\sigma_{1}=\sigma_{2}=\ldots=\sigma_{N}
$$

and from equation 5-3,

$$
E(N)=\sqrt{N \sigma_{1}^{2}}=\sqrt{N} \sigma_{N}
$$

The actual signal-to-noise ratio of the decoded pulsecoded signal is.

$$
S / N_{P C}=\frac{N}{\sqrt{N} \sigma_{N}}=\frac{\sqrt{N}}{\sigma_{N}}
$$

From equations 5-1, 5-2 and 5-6, it seems that

$$
S / N_{P C}=\frac{\sqrt{N}}{\sigma_{N}}=\frac{\sqrt{B W T}}{\sigma_{N}}=S / N_{P M}
$$

Due to the pre-limiting, the $S / N$ ratios are also a comparison of maximum output signal level to Minimum Detectable pigral (MDS) level.

It should be noted at this time that with sidelobe enimination, both FNi and PC S1gnal-to-noIse natsos W11. decrease. According to C. E. Cook, ${ }^{7}$ the FM signal to noise will decrease by a factor of less than ldb. The PC signal-tonolse ratio will decrease by a factor of $\frac{1}{N}^{*}$ due to the subtraction of one-bit amplitude. For 7 bits, the $\mathrm{S} / \mathrm{N}$ decrease i.s $1.33 \mathrm{db}$; for 11 bits, the $S / N$ decrease is $0.83 \mathrm{db}$; and for 13 bits, the $S / N$ decrease is $0.69 \mathrm{db}$ 


\section{CONCLUSIONS}

the following conclusions can be drawn from this investigation:

A Phase-Coded compressible pulse can be generated by the use of equations 2-15, 2-16, and 2-17, set forth in chapter II. This Phase-Coded waveform, after being generated, may be recomined such that its amplitude is increased by the same factor that its width is decreased. As explained in the introduction, this new, reconstructed waveform provides finer range resolution for systems previously incorporating transmitted pulses which were the width of the Phase-Coded transmitted pulse. It is also shown that for systems incorporating transmitted pulses which were the width of the Phaseccded recombined pulse, an increased range capability evolves. The Phase-Coded method can be seriousiy affected by doppler aispersion if the proper choice of operating paramteers is not made. However, equation 3-1 in chapter III allows a rapid check to be made on what the half-power doppler velocities will be. When a definite bit width is chosen, and the maximum tolerable velocity is detemined, then the desfgner need only keep the (operation frequency)-(bit width) product from exceeding a design maximum.

Sidelobe generation is a by-product of both the FM oulse compression technique and the Phase-Coded pulse compression technique. However, the sidelobes can be eliminated 
by processes peculiar to each method. The Phase-coded sidelobe elimination method is a less involved process than that of the FN method (which requires elaborate weighting inters).

The signal-to-noise ratios for FM and PC compression were found to be the same as would be obtained from an energy standpoint. This equality could not have been assumed due to the unorthodox nature of the PC method. The comparison had to be made in order to insure that the sidelobes do not contain an excess of the information.

Mriginal. work by the author involved developing the general equations for determining the code logic in Chapter II, providing the overall Phase-Coded system block diagram, developing an equation to show the effects of doppler dispersion, providing a scheme for sidelobe elimination thus eliminating range ambiguities, and developing Phase-Coded relationships for a signal-to-noise ratio comparison. 
1. Schlesinger, Robert $J \cdot$, Principles of Electronic Warfare, Prentice-HaIl, Inc., Englewood Cliffs, New Jersey, 1961 (p. $86-89)$.

2. Horton, J.W., Fundamentals of Sonar, Library of Congress, 3rd Printing, June 1965.

3. Philips, C. F., A Four-Bit Variable Width Compressible Waveform, Westinghouse Electric Corp., Electronics Division, Baltimore, Ma., October 1962.

4. Cook, Charles E., "Pulse Compression-Key to More Efficient Radar Transmission," Proceedings of the IRE, March 1960.

5. Van Vleck, J. H. and David Midaleton, "The Spectrum of Clipped Noise," Proco of the IEEE, Jamuary 1966.

6. Reza, F. M., An Introduction to Information Theory, McGraw-Hill Book Co., 1961.

7. Cook, C. E., "General Natched Filter Analysis of Iinear FN Pulse Compression," Proc. of the IEEE, Vol. 49, Apri1 1961.

8. Remley, Winslow R., "Doppler Dispersion Effects in Matched Filter Detection and Resolution," Proc. of the IEEE, January 1966.

9. Cook, C. E. and W. H. Heiss, "Iinear FM Pulse CompresSion Doppler Distortion Effects," Proc. of the IEEE, Vol. 50, June 1962 . 
20. Davenport, W. B., Jr. "Signal-to-Noise Ratios in Bandpass Limiters," Journal of Applied Physics, Vol. 24, 1953. 


\section{Medin: Power Transducer \\ Masisa Model TR-55A}

The Model TR-55A was developed for use as a transponder for deep water oceanographic applications cperating over the frequency range of $9.5 \mathrm{kHz}$ to $12 \mathrm{kHz}$ as a transmitter and at $16 \mathrm{kHz}$ as a receiver

The TR-55A transducer amploys the use of lead zirconate ceramic as the active acoustical element contained within a castor oil filled cylindrical butyl bout, hemispherical at one end and attached to an aluminum mounting flange at the other end. High pressure electrical feed-throughs are mounted in the flange through which connection is made to the ceramic element.

A choke is supplied with taps for operation at $9.5,10,10.5$, 11, 11.5 and $12 \mathrm{kHz}$. A separate winding is provided to shunt tune the transducer at $16 \mathrm{kHz}$. When the choke is used, the power input

Mited to 30 watts cw or pulsed. The TR=5 5 A alone can be operated to 800 watts input cW.

The TR-55A is designed to mount as a cap on one end of a $T^{\prime \prime}$

diameter pipe. The transducer will operate to hydrostatic pressures of 10,000 psi.

Attachments:

SK -6179

SK -6180

SK -6181

SK- 6182

SK- -6178

$\mathrm{SK}-6177$

SK- -6184

C -30915

B- -21527
Transmitting and Receiving Response

Vertical Directional Response Frequency $9.5 \mathrm{kHz}$

Vertical Directional Response Frequency $12 \mathrm{kHz}$

Vertical Directional R sponse Frequency $16 \mathrm{kHz}$

Horizontal Directional Pattern

Linearity

Nominal Series Impedance

Outline of Transducer

Outline Tunirig Coil 
3 HE

$y$

a

io 1 ,

$\omega$

020.0

N $0<0$

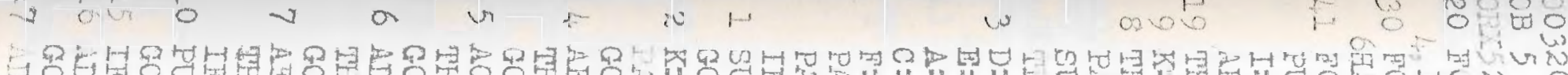

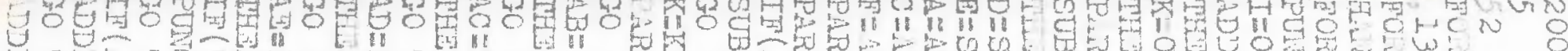
gat

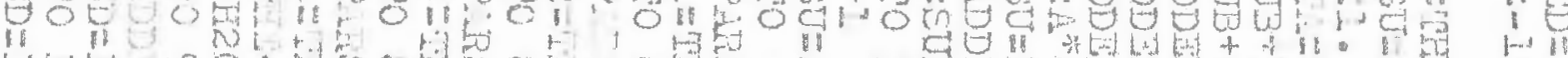

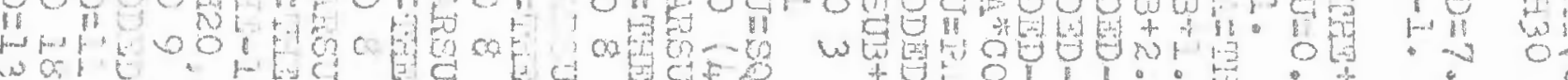

$$
\begin{aligned}
& \text { vis } \\
& 0 \\
& \text { 证 } \\
& -\theta \\
& \text { bi } \\
& 5 \\
& 8
\end{aligned}
$$

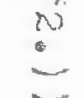$$
\text { it: }
$$$$
\text { (.) }
$$$$
\text { w } 1 \text { of on }
$$$$
\text { * }
$$$$
\text { tat }
$$$$
++6
$$$$
\text { - }
$$$$
p \rightarrow
$$$$
\text { to }
$$$$
\text { 要 }
$$$$
1
$$$$
-\infty
$$$$
0 \frac{1}{0}
$$$$
0:-1
$$$$
51+0
$$$$
\text { w. th }
$$$$
\text { Cot } x^{4} \text { क }
$$$$
\text { - vin o }
$$$$
\text { fw }
$$$$
\text { w) w }
$$$$
\therefore \text {. }
$$$$
\text { (1) }
$$$$
-v_{2}
$$$$
02 x^{2}
$$$$
-\infty v_{1}
$$$$
\text { S } 5
$$$$
2
$$$$
\text { tri }
$$$$
\text { ए. }
$$$$
\text { DU }
$$$$
5
$$$$
\omega_{1}^{2} 0
$$$$
\text { ix on }
$$$$
\text { un }
$$$$
+\rightarrow
$$$$
5
$$$$
+=
$$$$
\text { \& } 5
$$$$
\text { si }
$$$$
\text { in : }
$$$$
\text { in }
$$$$
\text { ti }
$$$$
+=
$$$$
\text { iv }
$$$$
\text { in }
$$ 


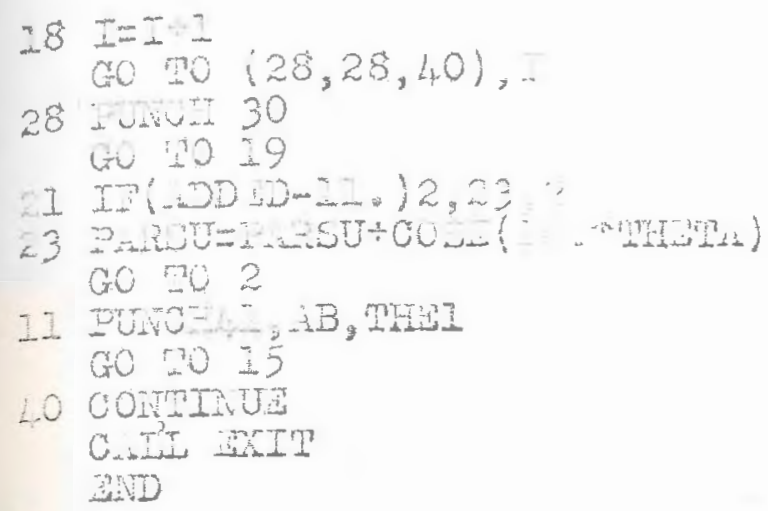

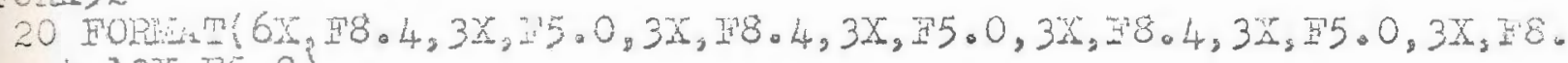
$4,13 x, 15.0\}$

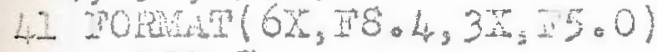

$A D D E D=7$.

1 DO2I $=1,4,5,1$

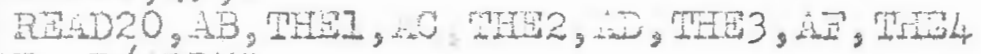
$A B=-3 / L D D D$

$\triangle C=A C / A D D B D$

$A D=S D / \therefore D D N D$

$A T=-T / D D D D$

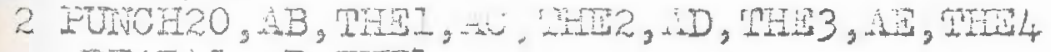
RTIDI, $2 B$, MLTEI

$A B=\angle B / \angle D D T D$

PUNCHAL, AB, WHEI

$I F(A D D E D-13) 11,$.40 , 0

21 IF( $A D D D D-11.) 26,17,17$

$16 \triangle D D P D=12$.

GO 101

$17 \mathrm{DDODD}=13$.

CO $\mathrm{PO} 1$

40 COMPINUP

CALL MPTI

MND 


\section{$\therefore-1$}

$\sum_{n=-\infty}(x-n) 000 \cdots$

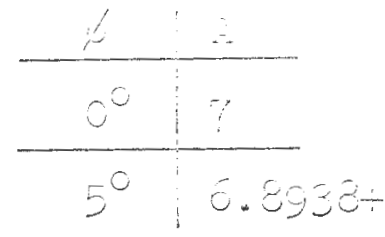

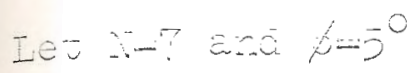

$A=-x$

$I=7 \div 2\left(60055^{0} \div 5000-0^{0}-4 \cos 15^{0} \div 300 s 20^{\circ}\right.$

$+200 \Omega 25^{\circ} \div 00030^{\circ}$

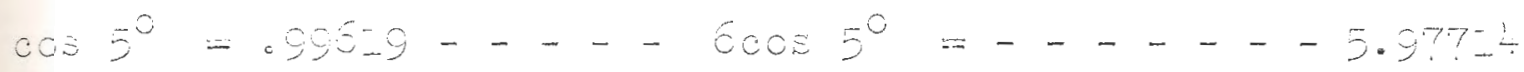

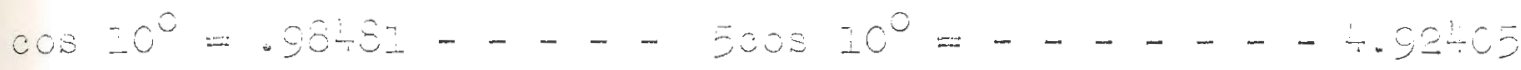

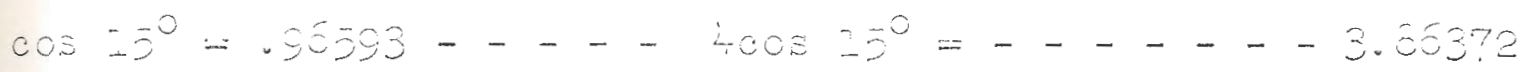

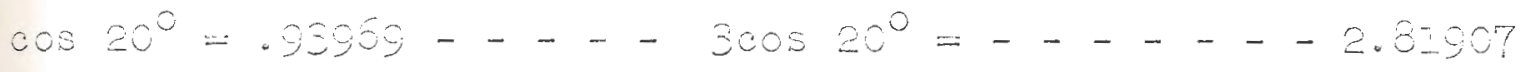

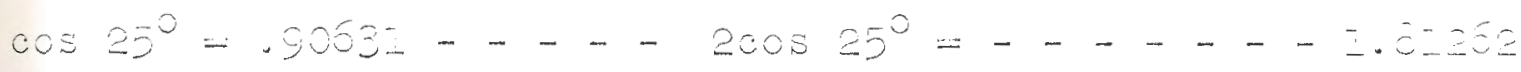
$\cos 30^{\circ}=.86603-\ldots+\cos 30^{\circ}=\ldots+\cdots-0.06603$

$$
\begin{aligned}
& 20.25263 \\
& +0.52526 \\
& \text { - ?.0000 } \\
& x=-7.52520
\end{aligned}
$$

$A=\bar{x}=6.09386$ 

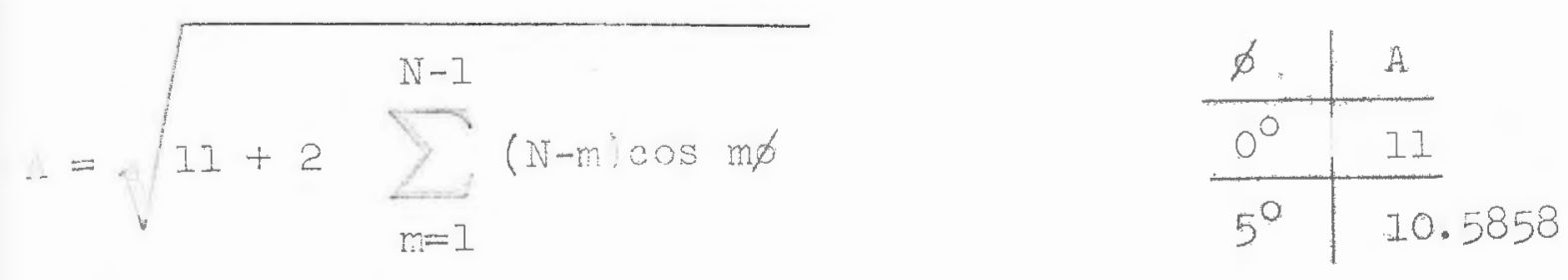

Let $N=1$ and $\phi=5^{\circ}$

$A=K$

$X=11+2\left(10 \cos 5^{\circ}+9 \cos 10^{\circ}+8 \cos 15^{\circ}+7 \cos 20^{\circ}\right.$

$+6 \cos 25^{\circ}+5 \cos 30^{\circ}+4 \cos 35^{\circ}+3 \cos 40^{\circ}$

$\left.+2 \cos 45^{\circ}+\cos 50^{\circ}\right)$

$\cos 5^{\circ}=.99619-\ldots-10 \cos 5^{\circ}=-\cdots-\cdots+-96190$ $\cos 10^{\circ}=.98481 \ldots+-9 \cos 10^{\circ}=\ldots-\ldots 86329$ $\cos 15^{\circ}=.96593-\ldots \cos 15^{\circ}=-\ldots-\cdots+72744$ $\cos 20^{\circ}=.93969-\ldots 700520^{\circ}=-\ldots-\ldots 7783$ $\cos 25^{\circ}=.90631 \ldots--6 \cos 25^{\circ}=-\ldots-\ldots-5.43786$ $\cos 30^{\circ}=.86603 \ldots-\ldots \cos 30^{\circ}=-\ldots-\ldots+43015$ $\cos 35^{\circ}=.81915-\ldots \cos 35^{\circ}=-\ldots-\ldots-27660$ $\cos 40^{\circ}=.76604 \ldots-\ldots \cos 40^{\circ}=\ldots-\ldots .29812$ $\cos 45^{\circ}=.70711 \ldots 2 \cos 45^{\circ}=\ldots-\ldots+\ldots 1.422$ $\cos 50^{\circ}=.64279 \ldots \cos 50^{\circ}=\ldots \ldots .64279$ $\frac{50.53020}{\mathrm{X} 2}$
$\frac{101.06040}{11.00500}$
$\mathrm{I}=\frac{0.61279}{112.06040}$

$A=\sqrt{K}=10.5858$ 

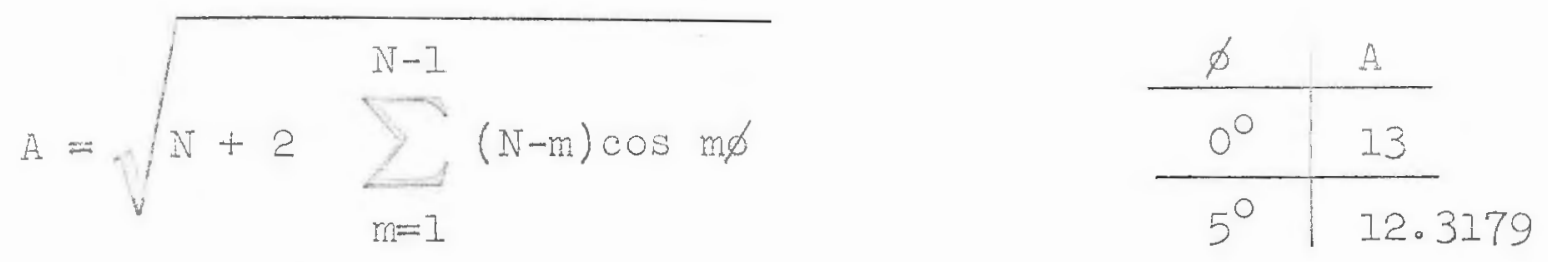

Let $N=13$ and $\phi=5^{\circ}$

$A=\underline{K}$

$K=13+2\left(12 \cos 5^{\circ}+11 \cos 10^{\circ}+10 \cos 15^{\circ}+9 \cos 20^{\circ}\right.$

$+8 \cos 25^{\circ}+7 \cos 30^{\circ}+6 \cos 35^{\circ}+5 \cos 40^{\circ}$

$\left.+4 \cos 45^{\circ}+3 \cos 50^{\circ}+2 \cos 55^{\circ}+\cos 60^{\circ}\right)$

$12 \cos 5^{\circ}-\ldots-\ldots+\ldots-\ldots 11 .+\ldots 5428$

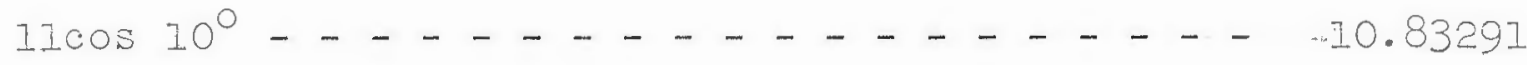
$10 \cos 15^{\circ}-\ldots+\ldots+\ldots .+\ldots .+\ldots 5930$ $9 \cos 20^{\circ}-\ldots+\ldots-\ldots+\ldots 45721$ $8 \cos 25^{\circ}-\ldots+\ldots+\ldots+\ldots .+\ldots 4048$ $7 \cos 30^{\circ}-\ldots-\ldots .+\ldots .+\ldots .+\ldots 6221$ $6 \cos 35^{\circ}-\ldots-\ldots+\ldots 4 .+\ldots$ $5 \cos 40^{\circ}-\ldots-\ldots+\ldots 3 .+\ldots-\ldots 3020$ $40085^{\circ}-\ldots \ldots \ldots-\ldots \ldots+\ldots, \ldots 284$ $3 \cos 50^{\circ}-\ldots-\ldots+\ldots-\ldots$ - $-\ldots 9837$ $2 \cos 55^{\circ}-\ldots-\ldots+\ldots+\ldots .+\ldots 4719$ $\cos 60^{\circ}-\ldots+\ldots, \ldots+\ldots, \ldots+\ldots 000$ 69.36546
$x \quad 2$

138.73092 $+\quad 13.00000$

$A=\sqrt{K}=12.31791$

$K=$ 151.73092 